\title{
FLEXIBILIZACIÓN DEL MERCADO DE TRABAJO Y PRECARIZACIÓN DEL EMPLEO. LA CONTRATACIÓN TEMPORAL: ASPECTOS TEÓRICOS, LEGALES E HISTÓRICOS
}

\author{
Carmen Bel Adell
}

\begin{abstract}
RESUMEN
Este artículo aborda los aspectos teóricos, legales e históricos de la contratación temporal y nos sitúa en la perspectiva conceptual que fundamenta la praxis resultante.

Palabras clave: contratación temporal, flexibilidad, precarización, empleo.
\end{abstract}

\begin{abstract}
This work approaches the theorical, legal, and historical aspects of the hiring of temporary workers, and places the reader in the conceptual perspective that lays the foundations of the resulting praxis.

Keywords: temporary labour hiring, flexibility, precarization, employment.
\end{abstract}

\section{Introducción}

Las Sociedades modernas de los PPDs, nadie lo duda, atraviesan desde hace unos veinte años una crisis profunda, calificada como crisis estructural del sistema e incluso de la propia civilización industrial.

Desde la perspectiva económica puede hablarse, desde finales de los 80 de una cierta recuperación y reactivación. Pero las secuelas de la crisis firmemente implantadas y sus expresiones concretas, paro todavía masivo, nuevas formas de pobreza y marginación social, emergencia y consolidación de una sociedad cada vez más desigual, y la incapacidad del sistema para dar solución a los viejos y nuevos problemas, cuestionan el orden existente.

La clave para interpretar la crisis y la superación de la misma, es múltiple y compleja, pero no hay duda que cualquier respuesta deberá pasar por el tema del trabajo, naturaleza y mutaciones que está experimentando el proceso productivo. Para bien o para mal, algo nuevo y distinto se está gestando; para bien, porque no cabe duda, de que los avances 
tecnológicos nos sitúan en el umbral de un salto cualitativo impensable hace treinta años y que hay que gestionar, «...constituye una aventura apasionante desde el punto de vista intelectual, científico y tecnológico al que la comunidad científica no renunciará». Para mal, porque las profundas transformaciones que se están verificando, lo hacen «...bajo la ley del más fuerte, sin contemplaciones, reforzándose al mismo tiempo las actitudes más insolidarias del liberalismo económico» (RIVA i ROMEVA, C. 1984).

El fantasma del «Mercado Total», (versión actualizada de los viejos principios liberales que subyugan a los nuevos economistas) donde todo se compra y todo se vende, está tomando cuerpo real, y el razonamiento económico, no sólo se aplica a las relaciones mercantiles, sino al conjunto de las decisiones sociales de los individuos ${ }^{1}$.

La innovación tecnológica y un mercado laboral flexible, son la «clave de bóveda» del orden laboral-económico emergente. La precariedad en el empleo es uno de los costes de la salida de la crisis que, exigía recuperar los niveles de beneficios y de acumulación capitalista que se habían perdido o disminuido durante los setenta. Y ello ha impuesto la flexibilización y abaratamiento del trabajo es decir, mano de obra desprotegida y vía libre a la contratación temporal; escasa contrapartida en materia de reciclaje ocupacional, presencia sindical debilitada... son piezas adecuadas para el puzle. La innovación tecnológica que junto a la utilización de técnicas de organización y gestión a «la japonesa» han de renovar la obsoleta estructura productiva, ha supuesto un aumento espectacular de la productividad y una sustitución de mano de obra por capital que «libera» o «desplaza» hacia otros lugares, dando origen al llamado paro «tecnoestructural», que según la OIT y la CE (Informe FAST) hasta la década de los cincuenta del siglo XXI no se preven cambios sustanciales en el volumen de desempleo.

Sobre este telón de fondo, diseñamos el cuadro de la precarización del empleo o contratación temporal.

\section{Aspectos conceptuales}

Flexibilización y precarización, dos términos que aplicados respectivamente a Mercado de Trabajo y Empleo, nos clarifican su ambiguo contenido.

El Mercado de Trabajo mediante la flexibilidad ha permitido la aparición de una variada gama de contratos de trabajo que desembocan en la precarización del Empleo, por sus efectos y la brecha que abre en el empleo típico o indefinido.

Esta formulación tan simple exige ser profundizada en virtud de la polémica suscitada entre los agentes sociales respecto al uso sancionado de estas expresiones con un sentido, que puede resultar, con frecuencia equívoco.

Las modificaciones profundas en el ordenamiento legislativo laboral que se traduce en la vigencia de catorce modalidades contractuales, se han calificado indistintamente como flexibilidad en el mercado de trabajo o precariedad en el empleo. Expresiones ambas, lo suficientemente genéricas como para crear confusión, pues no es lo mismo flexibilización que precariedad.

Respecto a la flexibilización, el término hace referencia a un conjunto de prácticas muy diversas entre sí, que en relación al modelo típico de contrato indefinido de jornada completa, introduce variadas posibilidades. En sentido amplio podrían considerarse: a)

1 No es infrecuente escuchar la conveniencia de sustituir la Seguridad Social por un Seguro voluntario y libre que cubra las necesidades sociales. En estos días, 14, 15, 16 de mayo aparece en los medios de comunicación, la noticia sobre la ¿privatización de la Sanidad? 
contratación indefinida por períodos discontinuos o jornadas reducidas; b) contratación por un plazo limitado; c) reducción de los costes de resolución de los contratos para las empresas, con el correspondiente cargo sobre los trabajadores o la Administración; d) reducción de los costes de reclutamiento o búsqueda de trabajadores, para la empresa; e) reducción de los costes de formación de los trabajadores; f) reducción de los costes laborales de las empresas a cargo de la Administración de una parte de los mismos; g) medidas discriminatorias positivamente diseñadas para facilitar el acceso de determinados colectivos al mercado de trabajo. En sentido estricto, las prácticas que implican flexibilización real del mercado de trabajo son la a) y la b). Sin embargo la simultaneidad de elementos de flexibilización y las medidas de fomento de empleo y de formación, en la mayor parte de las formas contractuales más utilizadas en España, aconseja diferenciar ambos componentes.

El término precarización suele utilizarse como indicador de la convergencia de una serie de elementos que dejan al trabajador «en precario» y hacen referencia a: a) la propia duración del contrato temporal y limitada; b) salarios con frecuencia inferiores y ausencia de participación en beneficios no salariales; c) mayores dificultades en la defensa de los derechos del trabajador y en ocasiones indefensión; d) peores condiciones de trabajo; e) probabilidad mayor de prácticas contractuales ilegales o abusivas por parte de las empresas. Es de estas circunstancias, cuando se dan, de donde deriva la precarización, más que de la estricta temporalidad, por lo que conviene distinguir bien ambos conceptos, pues la temporalidad del vínculo contractual no tiene por qué implicar necesariamente precariedad, ya que, en ocasiones por causas determinadas, puede ser asumida e incluso preferida. Aquí vamos a utilizarlo en el sentido derivado de la generalización de las formas de contratación flexible, que desembocan en precarias por sus condiciones y efectos, e implican prácticas discriminatorias que contradicen el espíritu de la ley.

$\mathrm{Y}$ es que el empleo precario se define en relación al modelo de empleo que se ha ido creando a lo largo de los últimos años, dando a luz reglamentaciones legales derivadas de leyes ya promulgadas por los Estados o de Convenios Colectivos de empresas, ramas, etc. y que aportan en consecuencia un «nuevo modelo» de empleo que nada o poco tiene que ver con el modelo tipo, y que siempre significa, inestabilidad, temporalidad, límite, inseguridad.

Esta nueva modalidad de empleo afecta a aspectos muy diversos: duración, forma del contrato, vínculos con la empresa, duración de la jornada, remuneración, subsidios y beneficios, antigüedad, protección ante los despidos, etc. En definitiva tiende a evitar las reglamentaciones existentes en materia de relaciones de trabajo, calificadas por los empresarios como «rígidas». La superación de estas rigideces confiere al empleo precario unas características que lo configuran y son, movilidad forzosa en el tiempo y en el espacio, y la intercambiabilidad de los trabajadores.

$\mathrm{Su}$ manifestación es múltiple y se expresa en formas diversas: subcontratación, trabajo temporal, empleo a tiempo parcial, contrato de duración determinada, trabajo sumergido, contratos de Formación, Prácticas... etc., formas que se analizarán en su momento.

\section{Marco legal}

\section{Contratación laboral en los países de la CEE: modalidades y características}

Entre los países de la CEE existe una gama amplia de modalidades de contratación laboral. Esta heterogenidad se debe no sólo a las distintas tradiciones de las relaciones 
laborales, sino también, al hecho de que la regulación de las denominadas formas atípicas y modificaciones posteriores, han tenido lugar en momentos diferentes y en etapas del ciclo económico y situaciones muy diversas de sus respectivos mercados de trabajo.

No se intenta hacer una enumeración exhaustiva, sino tan sólo, acotar los márgenes en los que se mueven las distintas prácticas nacionales y en lo que se refiere a contrataciones por tiempo no indefinido para que sirva de marco referencial y comparativo con la situación en España. En este caso se tratan en primer lugar algunos aspectos de tipo formal y en segundo lugar las características más significativas desde el punto de vista económico.

\subsection{Contratación temporal}

- Algunos aspectos formales

Respecto a las normas jurídicas que regulan la contratación temporal, su diversidad es amplia. Países que no imponen restricciones específicas sobre la contratación son: Dinamarca, Irlanda y el Reino Unido; Países que han promulgado leyes específicas: Bélgica, España, Francia, Italia, Luxemburgo y Portugal; los restantes países, Alemania, Grecia y Holanda regulan este tipo de contratos por medio de la legislación general sobre contratación.

Otro aspecto, el de la representación sindical, también ofrece variedad: es plena en Bélgica, Dinamarca, Francia, Grecia, Holanda, Italia, y Luxemburgo; no existe en Alemania y Portugal; es parcial en Francia; y se exige un período mínimo, entre tres y seis meses, para que los contratados tengan derecho a voto en Bélgica, Holanda y España.

La Administración Pública tiene algún papel interventor, pero siempre modesto, en España (registro en el INEM), Holanda y Luxemburgo.

— Características más significativas desde la perspectiva económica

Como aspectos más sustantivos por la incidencia en el contratado, cabe destacar tres: requisitos exigidos para la contratación no indefinida, la duración de la misma, y las posibilidades de renovación.

En cuanto a los requisitos exigidos y su extinción automática en el plazo fijado por el contrato, los países comunitarios pueden agruparse en dos bloques: Bélgica, Dinamarca, España, Holanda, Irlanda y Reino Unido, no exigen requisitos específicos. Los restantes países sí establecen alguna circunstancia específica para esta modalidad contractual; su inclusión en este grupo no significa que coincidencia en las condiciones requeridas, siendo grande la heterogeneidad.

En relación a la duración de los contratos, de nuevo la diversidad y la existencia de dos grupos de países: aquéllos en que no se establecen límites: Dinamarca, Grecia, Holanda, Irlanda, Luxemburgo y Reino Unido; y los que imponen límites temporales máximo y/o mínimo, los restantes. En este grupo la temporalidad es muy variable: Portugal sólo limita el máximo si se trata de renovaciones; España fija un máximo de tres años; Bélgica y Francia, dos años; Alemania año y medio ampliable a dos para contrataciones especiales, e Irlanda fija máximos variables que van desde los tres meses a los dos años. Períodos mínimos se exigen en España, Francia y Luxemburgo.

En cuanto a las posibilidades de renovación y posible conversión del contrato atípico en indefinido, la casuística es aún mayor pero podrían distinguirse cuatro grupos: Países que no imponen restricción alguna: Dinamarca, Irlanda y el Reino Unido. Países que limitan el número de renovaciones: Francia y Grecia a dos, Italia admite una única renovación excepcional y de igual duración al contrato inicial; Holanda admite una sola renovación 
con autorización administrativa expresa. Países que no limitan el número de renovaciones, pero sí el tiempo conjunto máximo: España y Portugal tres años. Finalmente Alemania no impone limitación pero exige la justificación de la temporalidad; en Bélgica la renovación concedida implica conversión en definitivo a menos que medie acuerdo entre la empresa y el trabajador. La conversión del contrato temporal en indefinido es automática si se sobrepasa la fecha de aquél en Bélgica, España, Francia, Grecia, Italia y Portugal; en Holanda y Luxemburgo implica una prórroga automática por igual plazo, con un máximo de un año.

\subsection{Contratación para aprendizaje}

Es general en los países de la CEE algún tipo de contrato en el que el empleador se compromete a enseñar la actividad y el contratado a aprenderla y trabajar en la empresa de dicha actividad. Este tipo de contrato suele tomar la forma de contrato de aprendizaje y se encuentra regulado por leyes específicas por no ser considerados como contratos laborales ordinarios. Las condiciones más destacables son: las restricciones a la edad máxima de los contratantes, 18 años en Bélgica y 29 en Italia. Límite en la duración máxima del contrato, oscila entre los tres años en Francia y cinco en Grecia e Italia. En tercer lugar, no suele haber vinculación contractual alguna entre el aprendiz y la empresa cuando se ha cumplido el proceso de formación; Francia e Italia conceden cierta prioridad a los aprendices para su posterior contratación. Por último, el salario es siempre menor que el de un trabajador ordinario y se fija según criterios diferentes: el SMIG en Francia; salario mínimo del puesto de trabajo concreto en Bélgica, o el salario normal en la empresa, en cuyo caso resulta muy próximo al salario completo como en Italia que oscila entre el 80 y 92 por ciento, o muy alejado como en el caso de Grecia que puede ser entre el 20 y el 80 por ciento.

En España las modalidades «en formación» y «prácticas» presentan el equivalente a esta contratación europea y tienen algunos elementos comunes.

\subsection{Otras formas de contratación}

En el conjunto de los países integrantes de la CEE se observan algunos contratos específicos, tales como: contratos realizados a través de una agencia de colocaciones especializada o empresa de trabajo temporal, prohibidos en España, Grecia e Italia; no regulados en Portugal; y permitidos con distintas regulaciones en los restantes países de la CEE. Contratos a tiempo parcial con regulación específica en España, Alemania, Francia. Contratos de trabajo compartido tienen cierta importancia en Alemania y Reino Unido. Modalidades de contratación intermitente que sólo incluye alguna protección legal en los casos de Alemania, España y Francia. Contratos de solidaridad en España, Francia e Italia. Y contratos de trabajo comunitario, reconocidos únicamente en Bélgica, España, Francia y el Reino Unido.

De esta breve síntesis se desprende que no existe un «modelo comunitario» en cuanto a formas de contratación atípicas. No obstante en la práctica negocial, la CE reduce la utilización de los contratos temporales a supuestos en los que existe un motivo justificado y coyuntural, no habitual, desestimándose su utilización incontrolada como ocurre en la práctica en España desde que se adoptó la modalidad de contratación temporal para el Fomento de Empleo, más allá de las limitaciones establecidas en el Real Decreto regulador.

Un dato interesante es la no correlación entre el grado de desarrollo económico y de 
regulación protectora de los trabajadores, puesto que Alemania ofrece una de las legislaciones más restrictivas en cuanto a contratación laboral, mientras que Portugal tiene muchos elementos que lo acercan al modelo más flexible, así como España (SEGURA y Otros, 1991).

\section{Propuestas de Directivas del Consejo}

Ante la progresiva flexibilización y precarización del empleo la Comisión de la CEE presentó en agosto de 1990 tres Proyectos de Directivas (CEE, agosto 1990), cuyos aspectos fundamentales son los siguientes:

Un primer proyecto sobre la base del artículo 100 del Tratado de Roma contempla las relaciones de trabajo a tiempo parcial (cuya duración semanal sea no inferior a ocho horas de trabajo), y los contratos temporales, los contratos de temporada o estacionales y establece unas normas de garantía: principio de igualdad de trato en relación con los trabajadores a tiempo completo o indefinido, en cuanto se refiere al acceso a la formación profesional en las empresas, a las prestaciones en especie y en metálico de los regímenes de asistencia social y de Seguridad Social no contributiva, y a los servicios sociales de la empresa. La protección del acceso al empleo estable de los trabajadores afectados, por lo que han de ser informados de la contratación de trabajadores a tiempo completo o indefinido, al objeto de que puedan ser consideradas sus candidaturas, y adoptar en consecuencia las medidas para que se anulen las cláusulas que prohiban la contratación de un trabajador temporal. Así mismo garantizar el cumplimiento de las obligaciones de las empresas de trabajo temporal, en especial el pago de salarios y cotizaciones a la Seguridad Social. Y finalmente la obligación del empresario de indicar en el contrato de trabajo, el motivo del recurso a este tipo de relaciones de trabajo, e informar a los representantes de los trabajadores su propósito de recurrir a ellas. Estos trabajadores temporales deben ser tenidos en cuenta, proporcionalmente a la duración de sus prestaciones, para el cálculo de los efectivos de la empresa a efectos de los órganos de representación de los trabajadores en la misma.

La segunda propuesta sobre la base del artículo 100A del Tratado, pretende evitar las distorsiones de la competencia que puedan deducirse de la utilización de dichas modalidades de contratación. Las normas se dirigen a: garantizar el principio de igualdad en el trato en cuanto a los regímenes legales y profesionales de Seguridad Social (teniendo en cuenta la duración del trabajo y/o la remuneración), lo relacionado con permisos anuales, indemnizaciones por despido o por antigüedad. Fija un límite a la renovación de las relaciones de trabajo temporal para un puesto determinado y de una duración no mayor de doce meses, de forma que, el total de períodos de empleo no exceda de treinta y seis meses; y la previsión de una indemnización equitativa en caso de interrupción no justificada de la relación de trabajo.

El tercer proyecto de directiva, sobre la base del artículo 118A del Tratado, contempla las medidas tendentes a promover la mejora de la seguridad y de la salud de los trabajadores temporales garantizándoles los mismos beneficios y para ello se requiere: precisar en el contrato la cualificación exigida, el lugar de trabajo, el horario, las características particulares del puesto de trabajo y la peligrosidad del mismo, dando a conocer al trabajador todos estos elementos. La empresa debe responsabilizarse de las condiciones de seguridad, salud e higiene exigidas para la ejecución del trabajo. El trabajador antes de asumir una actividad que precise cualificaciones o aptitudes profesionales particulares o una vigilancia médica especial, debe ser informado de los riesgos que afronta y recibir, en su caso, la formación adecuada. No debe recurrirse a un trabajador temporal para el desempeño de trabajos que 
requieran una vigilancia médica especial de larga duración y si excepcionalmente se hace, garantizar al trabajador un control médico más allá del período de su contrato.

La adopción de estas Directivas no parece exigir grandes modificaciones en el ordenamiento español, lo cual destaca su carácter marcadamente «posibilista». Tratan de establecer un «mínimo social comunitario» de aplicación a todos los Estados miembros de la Comunidad, mejorable por medio de la normativa propia de cada país, o a través de la negociación colectiva entre las fuerzas sociales» (ROJO TORRECILLA, E. 1991). Sin embargo, analizadas y puestas en práctica con minuciosidad podrían mejorar las condiciones de trabajo, seguridad e higiene de los trabajadores/as y cierto freno a posibles concesiones no deseables.

\section{Evolución reciente de la legislación laboral española en materia de contratación temporal}

El marco global de las relaciones laborales en España se vio modificado por un proceso que viene marcado por unos hitos fundamentales: El Estatuto del Trabajador, Ley 8/1980 de 10 de marzo y Ley 32/1984 de 2 de agosto de la Reforma del Estatuto del Trabajador, que complementó y corrigió sustancialmente algunos aspectos relativos al desarrollo y creación de determinadas formas de contratación; y posterior publicación de los Reales Decretos de regulación de las distintas modalidades contractuales (ver legislación).

El derecho al trabajo ha mantenido tradicionalmente entre sus principios generales, la estabilidad en el empleo y así era recogido en las Leyes y Normas de derecho interno, Ley del Contrato de Trabajo de 1944 y Ley de Relaciones Laborales de 1976. Esta última consagró por primera vez en el ordenamiento español, la preferencia por el contrato de trabajo de duración indefinida, ya que la del 44 dejaba a la voluntad de las partes la posibilidad de optar por la duración fijada previamente, o por el carácter indefinido del contrato. Sin embargo durante la vigencia de esta Ley, hubo una clara prevalencia de este tipo de contratación, debido a la normativa reglamentaria (Reglamentaciones de Trabajo y Ordenanzas Laborales) y a la Jurisprudencia que sentó el principio de que la duración determinada del contrato sólo era admisible cuando la naturaleza de la prestación contratada así lo justificara.

En consecuencia, legislativamente ha prevalecido el principio de preferencia por la contratación indefinida y la consiguiente regulación limitativa de las posibilidades de contratación de duración determinada. En realidad se trataba de armonizar la duración del contrato y la actividad: a una actividad estable y permanente un contrato indefinido, sin posibilidad de pactar lo contrario (CC.OO. 1991).

En los Pactos de la Moncloa, se encuentra el origen de normas coyunturales sobre política salarial, de rentas y empleo, que han ido suavizando esta situación vivida por algunos, como rígida.

La Ley 8/1980 del Estatuto del Trabajador, que modifica sustancialmente las relaciones laborales, es el primer intento legislativo de flexibilización y correspondiente precarización en materia de contratación, mediante las modalidades de contrato temporal y que con algunos matices y retoques se mantiene en la misma línea que la Ley de 1976. No obstante permanece en su artículo 15.1 la presunción de que el contrato de trabajo es concertado por tiempo indefinido, pero admite la posibilidad de hacerlo de duración determinada por tres motivos: a) para obra o servicio determinado; b) por razones eventuales (de temporada, aumento coyuntural de una actividad...); c) para la sustitución de un trabajador permanente con derecho a reserva del puesto de trabajo. A todo esto se añade la 
regulación del trabajo fijo de carácter discontinuo, y se admite (aquí se abre el portillo) la posibilidad de que el Gobierno pueda utilizar la temporalidad como incentivo para la generación de Empleo.

La verdadera aportación del Estatuto del Trabajador completada por el R.D. 2303/80 de 17 de octubre, es el mantenimiento de la tradicional preferencia por el contrato indefinido y la excepcionalidad de la contratación de duración limitada por las causas citadas.

La exigencia de flexibilidad económicamente insolayable trata de ser satisfecha dando cobertura legal a la permisión de contratación temporal inspirada, al margen de las condiciones explicitadas, en motivos de fomento de empleo. Es en este ámbito donde el ordenamiento laboral español muestra un mayor dinamismo, sucediéndose una serie de normas que culminan con el R.D. 1445/82 de 25 de junio. En él se trata de unificar las distintas modalidades de fomento de empleo con una amplia permisión de la contratación temporal en la perspectiva de promoción de empleo. Con mínimas modificaciones introducidas por el R.D. $3887 / 82$ de 29 de diciembre se mantiene en vigor hasta la reforma del Estatuto.

El segundo momento clave es la Ley $32 / 1984$ de 2 de agosto que apostó por la liberalización contractual y junto a la normativa reglamentaria que derivó de la misma, configura el panorama normativo existente en relación a las modalidades de contratación temporal. Con ella España se sitúa en la práctica a la cabeza de los ordenamientos europeos en la llamada «flexibilidad de entrada».

El eje de la reforma flexibilizadora se concreta en tres líneas fundamentales: 1) ampliación del ámbito de contratación temporal considerado normal; 2) flexibilización al máximo de la contratación temporal al admitir la misma con la exclusiva justificación de fomento de empleo (cuando antes se insistía en la excepcionalidad); 3) la normalización de otras modalidades de contratación y en especial del contrato a tiempo parcial.

1) La ampliación del ámbito de contratación temporal, se expresa en la creación de un supuesto nuevo de contrato, el de la «nueva actividad» por parte de la empresa, aunque se mantiene el artículo 15.1 del Estatuto.

Su desarrollo por R.D. 2.104/84 de 21 de noviembre precisa algo más el régimen jurídico anterior de estas modalidades contractuales y no en sentido permisivo: se identifican estos contratos con mayor precisión, «para trabajos con autonomía y sustantividad dentro de la actividad de la empresa»; de duración limitada en el tiempo, y establece el derecho de los trabajadores así contratados a percibir complementos por antigüedad en función del tiempo trabajado. También limita la duración máxima de los contratos eventuales a seis meses sin prórroga. En los contratos de interinidad o sustitución, cuando la reincorporación del trabajador sustituido no se produce a su debido tiempo el contrato se transforma en contrato por tiempo indefinido. Por su contenido, esta modalidad configura lo que podría calificarse de «período de prueba» para la empresa, en la línea de suprimir resistencias a la inversión creadora de puestos de trabajo. La fuente de inspiración de esta nueva figura, fue el Proyecto de Directiva Comunitaria de 30 de abril de 1982 que no fue confirmada posteriormente y se consolida con una gran flexibilidad, tal como muestra el texto.

2) La temporalidad como instrumento de fomento del empleo, se sustenta en una filosofía de mayor flexibilidad de contratación temporal y abre el abanico de las posibilidades al alcance del empresario para vencer resistencias a la contratación estable.

El R.D. 1.989/84 de 17 de octubre, da un paso más en esta vía al permitir que se celebren contratos de duración determinada cualquiera que sea la naturaleza temporal o 
permanente del trabajo a desarrollar, con desempleados inscritos en las Oficinas de Empleo. Con la supresión de «...hasta tanto subsistan las actuales circunstancias de empleo», parece indicar la admisión de que estas modalidades de contratación van a existir permanentemente. Las reglas de extinción y denuncia son generales con sólo unas mínimas reglas de garantía: indemnizar al trabajador con doce días por año de servicio; prohibición de contratar con esta modalidad en tres supuestos, y ciertas formalidades como dar el contrato por escrito y en el modelo oficial.

Con este Real Decreto, es importante destacarlo, se abre una brecha considerable en el esquema de modalidades de contratación que establece el artículo 15 del Estatuto del Trabajador ya previsto en el punto dos, donde encuentra su fundamento de derecho, puesto que en función del mismo y en la práctica, implica que es posible en todo caso la contratación temporal de cualquier trabajador. Si las condiciones en que puede recurrirse a esa modalidad son ya de por sí, muy flexibles, el régimen jurídico previsto, confirma esa flexibilidad. La duración máxima se amplía a tres años y sólo se impone un mínimo de seis meses.

Esta modalidad de contratación para el fomento del empleo supone en el sistema de relaciones laborales español, una gran amplitud a la contratación temporal.

3) La contratación a tiempo parcial, o combinada con otras actividades, en particular formativas, es otra modalidad flexible introducida. Esta figura no conocía regulación expresa antes del Estatuto de los Trabajadores, si bien nada impedía recurrir a ella.

El Estatuto la limitó a una función impropia y coyuntural de incentivo directo a la generación de empleo al reservar esta posibilidad a determinadas categorías de trabajadores. La reforma de 1984 abandona esta utilización coyuntural y acepta pueda regularse para que cumpla las funciones específicas en el mercado de trabajo y no se limite a colectivos concretos. Por tanto el contrato a tiempo parcial está abierto a cualquier trabajador, e incluso a perceptores de subsidio de desempleo, y pueden incluso transformarse de contratos a tiempo completo en contratos a tiempo parcial en las condiciones establecidas por convenios colectivos.

Otra modalidad es el contrato de relevo y la jubilación parcial como medida típica de reparto voluntario de trabajo. Los trabajadores con 62 años que cumplan los requisitos para tener derecho a la jubilación, puede transformar su contrato a tiempo completo por otro a tiempo parcial para poder contratar a un trabajador desempleado. Su regulación es muy flexible, salvo en la exigencia de que la distribución del tiempo trabajado sea por mitades. Producida la jubilación, el contrato puede extinguirse, continuar a tiempo parcial o convertirse en definitivo. Estas tres modalidades están reguladas por el R.D. 1991/1984 de 31 de octubre.

El R.D. 1992/1984 de 31 de diciembre, regula dos figuras de contratación temporal que merecen una atención especial por estar dirigidas a ampliar las posibilidades de contratación de los jóvenes; éstas son, el contrato en prácticas y el contrato para la formación.

Hasta la reforma de 1984 una visión parcial acentuaba la función coyuntural de discriminar positivamente el empleo juvenil; sin embargo, ambas modalidades han cumplido dos funciones de carácter más permanente: una sería la de establecer sistemas de capacitación de los trabajadores en conexión con la prestación efectiva de trabajo; otra facilitar los procesos de selección de la mano de obra a las empresas con un conocimiento de su rendimiento efectivo en el proceso productivo. Las reformas normativas de 1984 tienden a flexibilizar el régimen jurídico de estas modalidades potenciando el cumplimiento de las funciones atribuidas a las mismas.

El contrato en prácticas pueden concertarlo quienes están en posesión de determinadas 
titulaciones para completar los conocimientos adquiridos con la práctica, ampliando de este modo su campo de aplicación mediante tres situaciones: a) mayor número de titulaciones que permiten el recurso al contrato, que en la práctica es cualquiera que habilite legalmente para la práctica profesional; b) se amplía el período durante el que puede hacerse el contrato a cuatro años; c) y también la duración máxima que es de tres años, siendo la mínima de tres meses y admite prórrogas si la duración del contrato es inferior a la máxima posible.

El contrato para la formación en el trabajo se dirige a conjugar la prestación laboral con finalidades formativas, y también se han añadido normas flexibilizadoras como: a) ampliación de la edad que cubre de los dieciséis a los veinte años; b) se amplía también la duración máxima a tres años, con un mínimo de tres meses con posibilidad de prórrogas como en el anterior; c) en las empresas pequeñas el cumplimiento de las obligaciones formativas pueden concentrarse o alternarse con las de trabajo efectivo y se reducen las exigencias que no pueden ser inferiores a la cuarta parte del tiempo total convenido, ni superiores a la mitad.

Como conclusión puede decirse, que el abanico de posibilidades de contratación ofrecido en el ordenamiento vigente es amplio, y las distintas figuras están reguladas de manera bastante flexible, con lo que, los contratos temporales se consolidan estructuralmente y se generalizan en la modalidad de fomento del empleo, al modificarse el ámbito subjetivo de aplicación, pues ya no se utiliza sólo para los trabajadores de edad avanzada y a los que acceden al primer empleo, sino a todos los demandantes de empleo.

Un tercer momento se iniciaría cuando con motivo de la negociación del punto 2 de la Plataforma Sindical Prioritaria «Revisión de las modalidades de contratación», el Ministerio de Trabajo se consideró incapacitado, en aquel momento, para tener una opinión adecuada sobre la contratación temporal y para superar este vacío solicitó, un Informe a una Comisión de Expertos que se creó al efecto. Esta necesidad sentida ante un caso y situación tan concreta, es un síntoma de que algo no funciona bien, dado el carácter instrumentalista que suelen tener estas Comisiones para dar largas cuando hay que abordar algún tema de interés. El mapa de la realidad laboral está sumamente delimitado como para no insistir en ello. Quizá menos conocido, por menos estudiado sea, las consecuencias a corto, medio y largo plazo, que la floresta contractual tiene realmente sobre el empleo y el mercado de trabajo en general y sobre el individuo en particular.

El «Informe sobre las Modalidades de Contratación en España» (SEGURA, J. y otros, 1991) fue elaborado y presentado el 20 de febrero 1991 por el Ministerio de Trabajo en la Comisión de Política Social y de Empleo del Congreso de los Diputados. Sin entrar en un análisis exhaustivo, pero sí en una valoración global, destacamos algunos aspectos. El tono del Informe en su conjunto, está más acorde con los criterios mantenidos por el Gobierno, que con la dramática realidad del mercado de trabajo ${ }^{2}$. Se sitúa de lleno en la tendencia real y flexibilizadora, puesto que no cuestiona la filosofía que sustenta la contratación temporal y por ende, elabora sus conclusiones a partir de esta aceptación. Juzga negativa la vía instrumental utilizada por el Gobierno al constatar las «disfuncionalidades que crea tanto jurídicas como económicas...» (C. 6, p. 126), pero considera «adecuado el funcionamiento del mercado de trabajo» (C. 10 p. 127). Esto supone, una consagración del contrato temporal de Fomento de Empleo, con alguna propuesta de retoque poco significativa en relación a la regulación actual vigente. Hecho que lleva aparejado el mantenimiento de una

2 Hay que recordar que se trata de un documento de trabajo elaborado a propuesta del Gobierno y sin que intervinieran las fuerzas sociales en la determinación de los expertos, circunstancia que al menos, cuestiona su objetividad. 
modalidad contractual que ha generado un alto nivel de precariedad, y rompe con el principio de causalidad contenido en la normativa europea contemporánea y es principio básico del derecho al trabajo.

El Informe viene a ratificar lo ya denunciado por CC.OO. y UGT, quiebra del modelo contractual vigente y la progresiva precarización del mercado de trabajo; y ante esta constatación más o menos velada, las Conclusiones y las Recomendaciones, tienen un sentido contrario a la necesaria contención de la flexibilidad creada y mantenida; «... constituye un instrumento ideal para justificar la presente situación de degradación del empleo y la elevadísima tasa de temporalidad, pero no se incluye solución alguna para los más de cinco millones de trabajadores afectados por la temporalidad...» (UGT, 1991). Las Recomendaciones abundan y ahondan la línea de precarización que alcanza al 32\% de los asalariados (EPA 4. ${ }^{\circ}$ trimestre 1990).

En síntesis, los cambios más bien retoques, podrían resumirse en: a) Modificación de la duración del contrato temporal de fomento del empleo y unificación entre éste y el eventual: dos años y tres meses de duración máxima y mínima para el primero y tres meses como máximo para el segundo. Se precisan más las causas que lo justifican y se evita su utilización en actividades de carácter fijo discontinuo. b) Legalización de las empresas de trabajo temporal que en la práctica ya existen y que la realidad comunitaria contempla. Esta permisividad exige se potencie el empleo público y se garanticen los derechos de los trabajadores/as y la responsabilidad de las empresas usuarias. c) Supresión de algunas modalidades contractuales como son por lanzamiento de nueva actividad y para mayores de 45 años y minusválidos. La escasa utilización de estas figuras convierten en irrelevante esta modificación. d) Modificación de la normativa reguladora del trabajo a tiempo parcial por la dificultad en la utilización de los módulos existentes. De prosperar esta propuesta se sentarían las bases para la incentivación jurídica de esta fórmula con el consiguiente avance de la precarización. La escasa práctica de la contratación de relevo, hace inoperante esta propuesta referida a esa forma contractual. e) Mayores limitaciones para los contratos en prácticas y para la formación; dada su abusiva utilización, resulta obvia la ampliación del mínimo de duración y la comprobación real de la formación. Y en lo que se refiere al contrato en prácticas, supone el reconocimiento de que el amplio abanico de titulaciones posibilita una utilización abusiva que en el $70 \%$ de los casos dicho contrato no alcanza los seis meses de duración. f) La prohibición del encadenamiento de contratos temporales y establecimiento de garantías para todas las modalidades. Se mantiene la temporalidad subjetiva por cualquier causa, en coherencia con las anteriores propuestas, pero se limita el período máximo (ROJO TORRECILLA, E. 1991). «En suma cabría afirmar que, una parte no irrelevante del Empleo generado en el período 1986-1990 por la economía española se ha debido a la mayor flexibilidad de las modalidades de contratación». C. 2, p. 124. ¿Qué más se podría añadir? ¿Acaso no constituye esta conclusión, un juicio definitivo? Pero avancemos un poco más.

En el plano de la reflexión y al hilo de la lectura de Conclusiones y Recomendaciones, se impone hacer algunas consideraciones sugeridas por las mismas. Resulta preocupante la tendencia hacia un mercado de trabajo menos intervenido, donde «...las sanciones administrativas vayan desapareciendo en favor de las decisiones judiciales rápidas...». Esta exigencia implica cambios de prácticas muy arraigadas y también introducirá «... cambios significativos en las funciones de la inspección de trabajo» (C. 11, p. 128). La posición que defiende «sencillez jurídica...» es positiva pero conlleva un riesgo al incidir en la línea de lo que la doctrina laboral ha calificado como proceso de desregulación, así como, en la introducción de formas y esquemas privativistas en el marco del derecho laboral, (CC.OO. 1991, p. 7).

Sorprende la afirmación de que «... la legislación española en el tema objeto de análisis, 
ocupa un posición intermedia dentro del abanico de las regulaciones de los restantes países miembros de la CEE...» (C. 12, p. 128), cuando los datos dicen todo lo contrario, catorce modalidades de contratación mantiene nuestro ordenamiento jurídico laboral frente a tres en Europa, resultando ser el más alto de la CEE. En contraposición, por los niveles de protección social en España nos situamos en la cola; mayor número de parados, doble de la media europea, y menor número de subsidiados. Asimismo, mientras en Europa se mantiene y respeta el principio de causalidad, en España no.

Tampoco parece aceptable la conclusión en la que se afirma, «... que cualquier modificación del marco legal de la contratación es muy deseable que obtenga un consenso amplio de las partes implicadas porque sólo de esta forma su grado de credibilidad y aceptación será satisfactorio...» ( C. 13, p. 129). Difícil acuerdo puede lograrse en una negociación que parte, como el propio Informe reconoce de una situación que «...el análisis realizado...ha permitido detectar numerosas disfuncionalidades...» (C. 6, p. 126). Hay aspectos que por ilegales son innegociables, y sólo pueden y deben ser corregidos por los poderes públicos.

Del análisis del Informe, brota una urgente necesidad de cambios profundos en las actuales modalidades de contratación para garantizar el freno a la destrucción de empleo fijo y disminuir sustancialmente el empleo temporal. Ello requiere revisar, con las partes implicadas, dichas modalidades contractuales para reforzar el principio de estabilidad en el empleo y restituir la causalización, cuando sea necesaria la contratación temporal.

El final de esta breve historia, parece ser, una clara opción en favor de la contratación temporal y atípica, la excepcionalidad de la contratación indefinida y un grave deterioro en la relación trabajo fijo-trabajo temporal.

\section{Contratación flexible y precarización del empleo}

En qué medida la contratación flexible, temporal en concreto, es factor de precariedad e implica peores condiciones para los trabajadores o permite prácticas contractuales no justificadas por la exigencias de productividad u organización que motivan este tipo de contratación? Estos aspectos y algún otro, serán objeto de análisis para apreciar y valorar su incidencia, ya que las garantías que prescribe para evitar el abuso de contrataciones en cadena ilegales, en la práctica habitual son obviadas con relativa facilidad por las empresas contratantes, con la colaboración en no pocas ocasiones del propio contratado y de los representantes de los trabajadores y sindicatos que como mal menor, ignoran las irregularidades.

En general la legislación y la Jurisprudencia no desvelan, en teoría, discriminación en la contratación temporal y por lo tanto ausencia de circunstancias de precarización; todo parece regulado para una correcta actuación. Sin embargo, la realidad y un análisis más profundo, dice y muestra algo muy distinto.

Es indudable que, algunos aspectos derivados de las formas de contratación flexible implican una precarización del empleo o más bien, precariedad para el trabajador como ponen de manifiesto los efectos nada positivos de la contratación temporal respecto a: las condiciones de trabajo, las posibilidades de utilización abusiva de la misma, y el trato diferenciado que puede hacerse en los Convenios.

En cuanto a las condiciones de trabajo podrían explicitarse tales como: Salario y beneficios no salariales; no parece existe distinción alguna en la legislación, aunque debe tenerse en cuenta que ambos extremos se concretan en la negociación colectiva, por lo que es ahí donde deben evitarse las limitaciones o exclusiones. El disfrute de las vacaciones también es reconocido con independencia del carácter temporal, pero es menos claro. Sin 
embargo ante el silencio del Estatuto del Trabajador y en contra de la Jurisprudencia y alguna normativa anterior a la Ley de Relaciones Laborales de 1976 la Jurisprudencia actual sostiene, en aplicación del art. 27.1 de la citada Ley y del art. 4 del convenio n. ${ }^{\circ} 132$ de la OIT, que cada año el trabajador tiene derecho a la parte proporcional de vacaciones. El régimen de despido se aplica por igual con la diferencia de que no cabe imponer la readmisión del trabajador más allá del momento de la extinción del contrato así como el abono del salario. Los beneficios derivados de la antigüedad, se reconocen sólo en los contratos para obra o servicio determinado por ser los que pueden tener una duración mayor, (aquí la exclusión es manifiesta). En cuanto a las condiciones de extinción del contrato se impone el respeto al «preaviso de extinción» de quince días, pero sólo se exige expresamente en los contratos de fomento del empleo, para obra o servicio determinado y en los de lanzamiento de nueva actividad. Los eventuales al no superar los seis meses no plantean problemas, por lo que el preaviso alcanza sólo a los de duración superior a un año. El acceso a los regímenes de la Seguridad Social se reconoce a los trabajadores temporales en las mismas condiciones que a los indefinidos. La dificultad proviene de no cubrir los períodos previos de cotización exigidos. Los derechos de representación de los trabajadores temporales están reconocidos y el Estatuto de los Trabajadores establece una regla de cómputo: los trabajadores vinculados por duración determinada superior a un año y los fijos discontinuos se computan como fijos de plantilla y los contratados por término de hasta un año según el número de días trabajados en el año anterior a la convocatoria de elecciones: un trabajador más por doscientos días trabajados. Los temporales pueden ser elegidos, sin que ello convierta el contrato temporal en indefinido; siendo así que el mandato normal es de cuatro años, no tiene demasiado sentido el candidato con contrato temporal. También se les reconocen importantes derechos de información y control a los representantes de los trabajadores a partir de la Ley 2/1991 de 7 de enero, de la que no se espera solución.

Otras condiciones de trabajo como pueden ser: categoría profesional, movilidad, tiempo de trabajo, modificación de las condiciones de trabajo, etc. no son objeto de previsión diferenciada y es frecuente situar el tema en el terreno de las relaciones y controles sindicales más que en el jurídico, cuando se alegan condiciones de cierta explotación.

En cuanto al trabajo a tiempo parcial, en nada se diferencia al del trabajador a tiempo completo, salvo en la reducción de la jornada. El contrato fijo de carácter discontinuo se configura legalmente como contrato por tiempo indefinido; y los contratos en prácticas y para la formación, están sometidos a un régimen jurídico específico determinado por sus finalidades que no cumplen y que están requiriendo modificaciones sustanciales que las acomoden a sus fines específicos.

Respecto al trato diferenciado en los Convenios Colectivos, debe tenerse en cuenta que la negociación colectiva que ha pretendido discriminar a los trabajadores temporales, ha sido desautorizada por la Jurisprudencia que aprecia reiteradamente la nulidad de las correspondientes cláusulas. Y esta Jurisprudencia ordinaria ha sido avalada por el Tribunal Constitucional que sostiene la no diferenciación de trato.

Otro capítulo de precarización sería el de las prácticas ilegales o abusivas de contratación que se podrían sintetizar en el encadenamiento de contrataciones temporales, ante el que el ordenamiento español se limita a establecer prohibiciones de contratación temporal para el fomento del empleo en algún supuesto, sin que diga nada respecto a las otras modalidades temporales. De lo que se desprende la posibilidad de múltiples combinaciones de contratos temporales «de distinta naturaleza» ${ }^{3}$. En este apartado se incluye la regulación del contrato

3 Para evitar los abusos, mejorar las condiciones de trabajo y mitigar la precariedad, USO ha elaborado un documento: «Propuestas de USO» Unión Sindical n.ำ 94, mayo 1991. 
de relevo que permite pueda extinguirse el contrato del trabajador que compartió el trabajo para permitir el relevo, al extinguirse aquel por alcanzar la edad de jubilación. No hay justificación alguna para esta regulación por lo que debe cumplirse la lógica del contrato de relevo que es, la consolidación del contrato a tiempo completo. Es fundamental evitar al máximo los defectos funcionales del mercado de trabajo, pero más decisivo es que «los empresarios dejen las prácticas contractuales injustificables desde el punto de vista técnico y económico y que los sindicatos sean coherentes en la defensa del empleo global» (SEGURA, J. 1991) y no se centren exclusivamente en el empleo fijo asalariado que asciende al $70 \%$.

\section{Conclusiones}

El propio Informe de la Comisión, tras analizar las distintas modalidades de contratación y demostrar que tienen todas las garantías, hace una recomendación, la 17 en la que dice: «Que se diseñe un sistema de garantías conjuntas para todas las modalidades... que evite el uso de las mismas como forma precarizadora del empleo». Si las garantías son plenas y la práctica cumple las condiciones, ¿por qué la recomendación y en términos tan precisos? ¿Acaso las recomendaciones no vienen a tratar de superar las irregularidades y los efectos precarizadores producidos?

Teóricamente se configura un bloque de garantías que no permite identificar temporalidad del vínculo y precariedad, aunque en la práctica cotidiana son dos realidades indisolubles, al menos para el trabajador. En alguna ocasión estas garantías pueden ser ampliadas por la negociación colectiva, pero no es frecuente: de los 196 Convenios publicados en el BOE en el período enero-septiembre de 1990, sólo doce contienen cláusulas prohibitivas o limitativas a la utilización de modalidades de contratación temporal (Informe, p. 24).

Se desprende de lo dicho, la necesidad de una regulación unitaria de las distintas modalidades de contratación en la que se establezca un régimen general de aplicación a todas ellas que impida cualquier posibilidad de encadenar contratos no indefinidos.

El Informe termina con unas serias lamentaciones (que son reales) sobre la insuficiente información estadística que posibilitara la confirmación empírica, y la complejidad jurídica derivada de la superposición del Estatuto del Trabajador, la Reforma de 1984 y las modificaciones jurídico-laborales en otros ámbitos, hasta el punto de que «...si se siguen sus recomendaciones, se produciría una nueva modificación sustantiva del marco legal vigente». Afirmación no compartida al considerar que sólo se sugieren correcciones y no se aborda una reforma en profundidad como lo exige el momento en que la contratación temporal afecta a un tercio de la población asalariada. Y continúa, «... en la línea de transparencia y simplificación de la norma legal defendida... la Comisión propone...» «se proceda a una nueva redacción del Estatuto del Trabajador que derogue toda la legislación previa en esta materia» (R. 18, p. 141). Y para superar las deficiencias estadísticas, «... que se potencien al máximo las instituciones encargadas de la recogida de información estadística relacionada con el Ministerio de Trabajo, dotándoles de los medios políticos y técnicos necesarios para llevar a cabo su labor». (R. 19, p. 142).

En definitiva puede concluirse, que la precariedad brota de la temporalidad, no en sí misma considerada, pero sí de la brevedad y delimitación temporal que impide beneficiarse de las garantías con que se dota al trabajo que legalmente está pensado como indefinido, así como, por la propia contradicción en la que incurre el trabajador que se ve obligado a la total asunción de las reglas establecidas por la empresa, ya que su cumplimiento aún ilegal, puede significar la renovación del contrato, aunque eventual de nuevo, eso sí. 
«Ningún sistema productivo que busque eficiencia puede edificarse sobre el empleo temporal, y en el sistema actual uno de cada tres trabajadores asalariados vive en precario» (ALBARRACIÓN, J. 1991).

\section{Fuentes}

1. Legislación

— Ley del Contrato de Trabajo de 1944.

- Ley de Relaciones Laborales de 1976

- Pactos de La Moncloa.

- Ley 8/1980 del Estatuto del Trabajador de 10 de marzo.

- R.D. $1445 / 82$ de 25 de junio.

- R.D. $3887 / 82$ de 29 de diciembre.

- Ley 32/1984 de 2 de agosto.

- R.D. $1.989 / 1984$ de 17 de octubre por el que se regula la contratación temporal de fomento de empleo (BOE n.․ 24.873).

- R.D. 1991/1984 de 31 de octubre por el que se regulan el contrato a tiempo parcial, el contrato de relevo y la jubilación parcial (BOE n. ${ }^{\circ} 24.875$ ).

- R.D. $2104 / 1984$ de 21 de noviembre por el que se regulan diversos contratos de trabajo de duración determinada y el contrato de trabajadores fijos-discontinuos (BOE n. .25 .805 ).

- R.D. 799/1985 de 25 de mayo por el que se incentiva la contratación de jóvenes trabajadores y se extiende esta medida a determinados programas y contratos vigentes (BOE n. ${ }^{\circ}$ 9.989).

- R.D. 1194/1985 de 17 de julio por el que se acomodan las normas sobre anticipación de la edad de jubilación como medida de fomento de empleo.

2. Estadísticas

- Instituto Nacional de Estadística: Encuesta de Población Activa (EPA).

- Ministerio de Trabajo y Seguridad Social: Boletines de Estadísticas Laborales (BEL).

- Instituto Nacional de Empleo: Estadísticas de Empleo.

3. Documentales

- Comisión de las Comunidades Europeas: Propuesta de Directiva del Consejo. COM (90) final SYN 280 SYN 281. Bruselas 16 agosto de 1990.

- CC.OO.: La actividad económica de la población española durante 1987-1989 y las politicas de empleo. Gabinete Técnico Confederal, abril 1990.

- CC.OO. (1991): Valoración de las C.S. del «Informe sobre las Modalidades de contratación en España». Gabinete Técnico Confederal, marzo 1991.

- SEGURA, J. (Presidente); DURÁN, F.; TOHARIA, L.; BENTOLILA, S. (1991): Informe sobre las modalidades de contratación en España (Conclusiones y Recomendaciones). Ministerio de Trabajo y Seguridad Social. Febrero 1991.

- U.S.O.: «Propuestas» y «Las modalidades de contratación laboral en España». Unión Sindical, n. 94 mayo 1991. 


\section{Bibliografía}

ALBARRACÍN, J. (1990): «La política económica y el empleo». II Jornadas de Economía Crítica. Bilbao, febrero 1990.

BARCALA, D. (1990): «La nueva configuración del paro obrero en España». N.O. n.ํㅜ 1.033 octubre 1990. Madrid.

BEL ADELL, C. (1991): «Generación de empleo en los últimos años: el empleo precario». $I I I .{ }^{\underline{a}}$ Jornadas sobre población española. Universidad de Málaga, pp. 221-230.

MINISTERIO DE ECONOMÍA Y HACIENDA (1989): «Informe de Coyuntura económica». Dirección General de Previsión y Coyuntura. 1989.

- (1989): «Escenario macroeconómico y presupuestario» 1988-1992. Madrid.

- (1990): «Informe Económico y Financiero de los Presupuestos Generales del Estado para 1990».

RIVA i ROMEVA, C. (1984): Nuevas tecnologías, Sociedad Capitalista y Paro. Universidad de Barcelona.

ROJO TORRECILLA, E. (1990): «La contratación temporal» N.O. n.ํำ 1.036 noviembre 1990.

- (1991) «Reforma de la contratación temporal: llegan los expertos». Caritas n.․ 308 abril 1991.

- (1991): «La Europa de dos velocidades». N.O. n.ำ 1.040, enero 1991.

SÁEZ, F. (1988): «Ayudas públicas a la creación de empleo en el sector privado: una evaluación» Economía Industrial. Enero-febrero 1988.

SEGURA, J. (1991): «La competitividad no es sólo costes». El País 7, julio, 1991. 